\title{
Bus bays inventory using a terrestrial laser scanning system
}

\author{
Katarzyna Bobkowska ${ }^{1, *}$, Jakub Szulwic ${ }^{1}$, and Pawet Tysiąc ${ }^{1}$ \\ ${ }^{1}$ Gdansk University of Technology, Faculty of Civil and Environmental Engineering, Gdansk, Poland
}

\begin{abstract}
This article presents the use of laser scanning technology for the assessment of bus bay geo-location. Ground laser scanning is an effective tool for collecting three-dimensional data. Moreover, the analysis of a point cloud dataset can be a source of a lot of information. The authors have outlined an innovative use of data collection and analysis using the TLS regarding information on the flatness of bus bays. The results were finalized in the form of colour three-dimensional maps of deviations and pavement type.
\end{abstract}

\section{Introduction}

Millions of people use roads every day all over the world. Roads, like many other structures, have an estimated durability of road types. In Poland a lot of the roads were built at the turn of the $20^{\text {th }}$ and $21^{\text {st }}$ c., especially for light cars [1]. Many of these roads carry traffic and heavy goods vehicles [2] which were not predicted when the road was first designed. It creates a lot of problems with technical conditions and the infrastructure must be improved. Treatments can be problematic, because restoring the original properties of the road requires workers to restrict traffic as cars may cause a lot of damage to the construction.

In small cities transport infrastructure is vital for regional growth. This is why it is important to maintain proper conditions to ensure optimal capacity. To support economic growth, new roads must be built. As indicated above, most of the roads were built at the turn of the $20^{\text {th }}$ and $21^{\text {st }} \mathrm{c}$. and a complete renovation is too expensive. To reduce the deterioration heavy vehicle traffic should be restricted by building ring roads. It is not possible to eliminate a degradation of roads because of public transport, where trams and buses operate in cities every day. Bus bays and the surfaces there are hardest hit by degradation. This paper shows a solution for making an inventory of bus bays and estimating their condition by using terrestrial laser scanning. This will support a proper analysis designed to find the best solutions to minimise the effects of heavy traffic on roads using the example of bus bays in Gdansk, Poland. While manual techniques could also be applied, they are often time consuming and the results are not accurate. To get a good understanding of the road conditions, it is better to use photogrammetry techniques.

\section{Data acquisition and data processing}

To acquire spatial data, the Riegl VZ-400 terrestrial scanning system was used (Fig. 1). A laser scanning system is an efficient tool for gathering spatial data with a very high accuracy

\footnotetext{
* Corresponding author: katbobko@pg.gda.pl
} 
(5mm [3]). In addition to ranging, Light Detection and Ranging systems can provide information about the target and transmission path [4]. In that option we could indicate the lanes and measure the geometry of every pavement type.

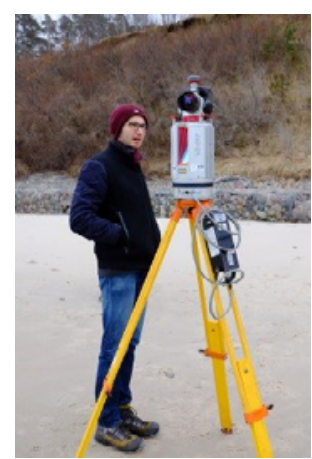

Fig. 1. Riegl VZ-400.

The experiment was conducted by scanning positions at the beginning and end of the bus bay. To be remembered is the traffic. While noise from the cars is easy to remove, it can leave a shadow which could cause unexpected errors in analysing (for example errors when meshing the data) the scanned object. The results of the alignment of the scanned bays are presented in Fig. 2.

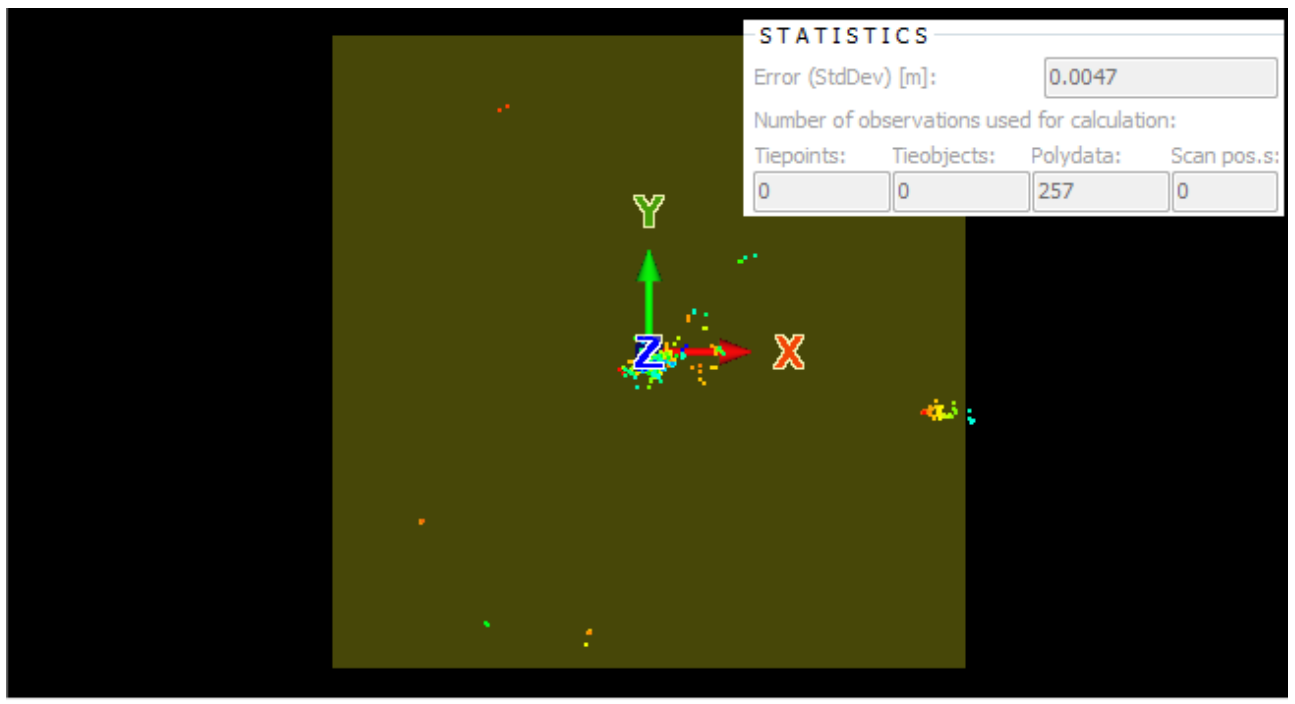

RESIDUES

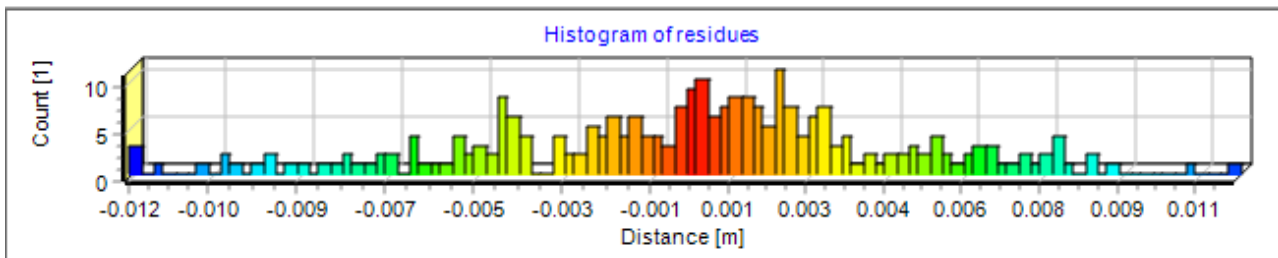

Fig. 2. Alignment of the scans results. 


\section{Classification of pavement condition}

Flatness is one of the parameters which could be used to determine the level of service. It is a condition that affects driving comfort. The main requirement is a good, strong, flat, waterproof, durable and economic solution over the life of the object [5]. To meet the requirements, monitoring and evaluation must be conducted regularly to ensure that the proper method is used for improvements to the structure [6].

For the purposes of this paper, the authors chose the classification of road condition set out in attachment $\mathrm{C}$ to the system for evaluating the condition of pavements created by the General Director for National Roads and Motorways. The road condition in addition to its rut depth is shown in the table below.

Table 1. Road class in addition to depth of ruts.

\begin{tabular}{|c|c|c|}
\hline Class & Pavement condition rate & Rut depth [mm] \\
\hline A & good & $11-20$ \\
\hline B & acceptable & $20-30$ \\
\hline C & not satisfactory & $>30$ \\
\hline D & bad & \\
\hline
\end{tabular}

The laser scanning technology is a very effective tool as regards its ability to search for deformations [7] but it is undervalued in indicating ruts. As a result, the table presented above is not reliable. The reason for that is another measurement methodology described in the pavement condition evaluation system. The authors show an innovative solution which could be successfully used in addition to ruts depth in the future [8].

\section{Experiment results}

For the purposes of this paper, two different types of bus bays were scanned. The first one was built from asphalt and the second one from sett. The results of the two scans are presented below (Fig. 3, Fig. 4).

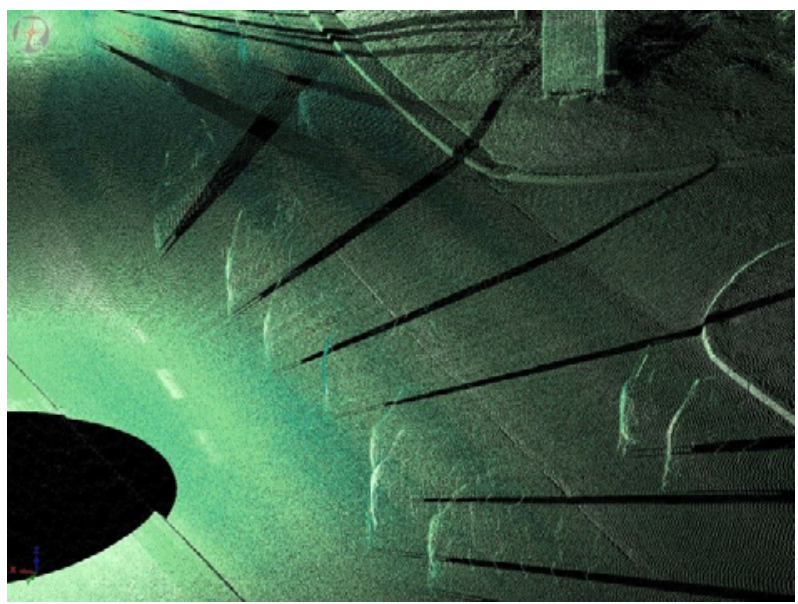

Fig. 3. Result of asphalt bus creek scanning. 


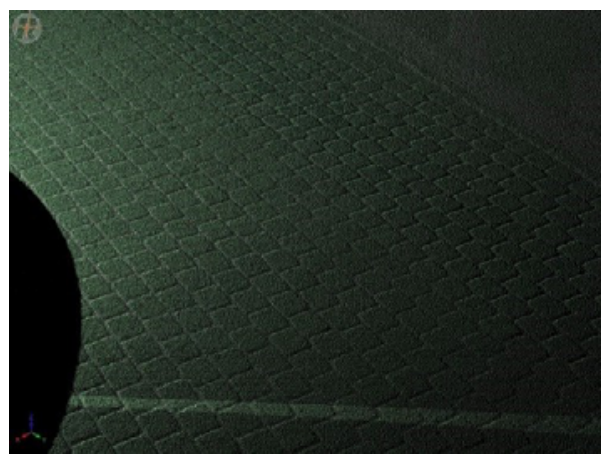

Fig. 4. Result of sett bus creek scanning.

\section{Bus creek condition}

In order to assess the condition of the bus creeks, geometry analysis was conducted in addition to the individual segments of transport infrastructure objects. During the study, the CloudCompare software was used. The analytical process was as follows:

a) Separation of the cloud of points representing the portion of the bus creek, which will be subjected to analysis [9],

b) Fitting a plane on a point cloud (RMS fitting method),

c) Development of three-dimensional maps of deviations,

d) Visualization of maps in mesh form [10].

This approach allows for a quick geometry assessment of the road surface. Below are the results of the study:

a) the concrete blocks creek- Fig. 5,

b) the asphalt creek-Fig. 6 .

Information on the selected points is displayed. In the yellow frame, the value of the deviation from the plane is indicated.

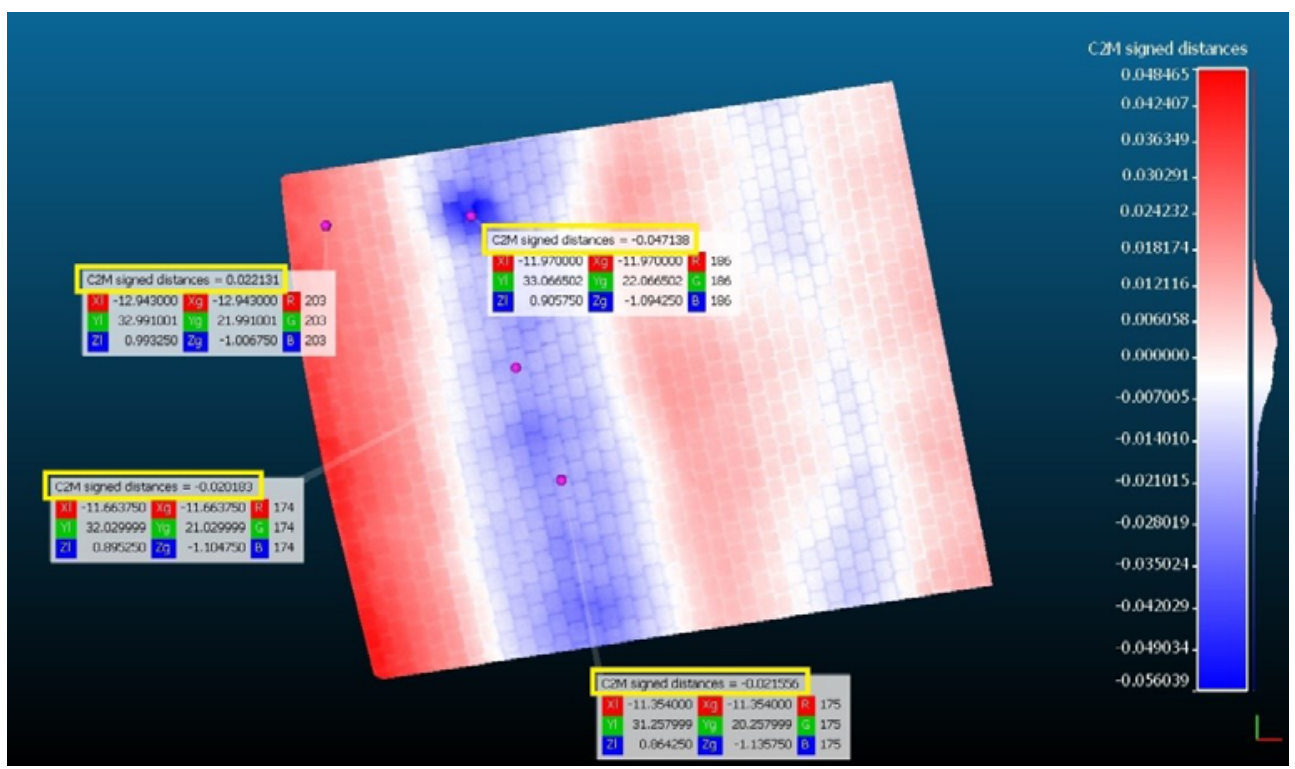

Fig. 5. Result of analysis of the segment ( $3.5 \times 4$ meters) creek with concrete blocks (units - meters). 


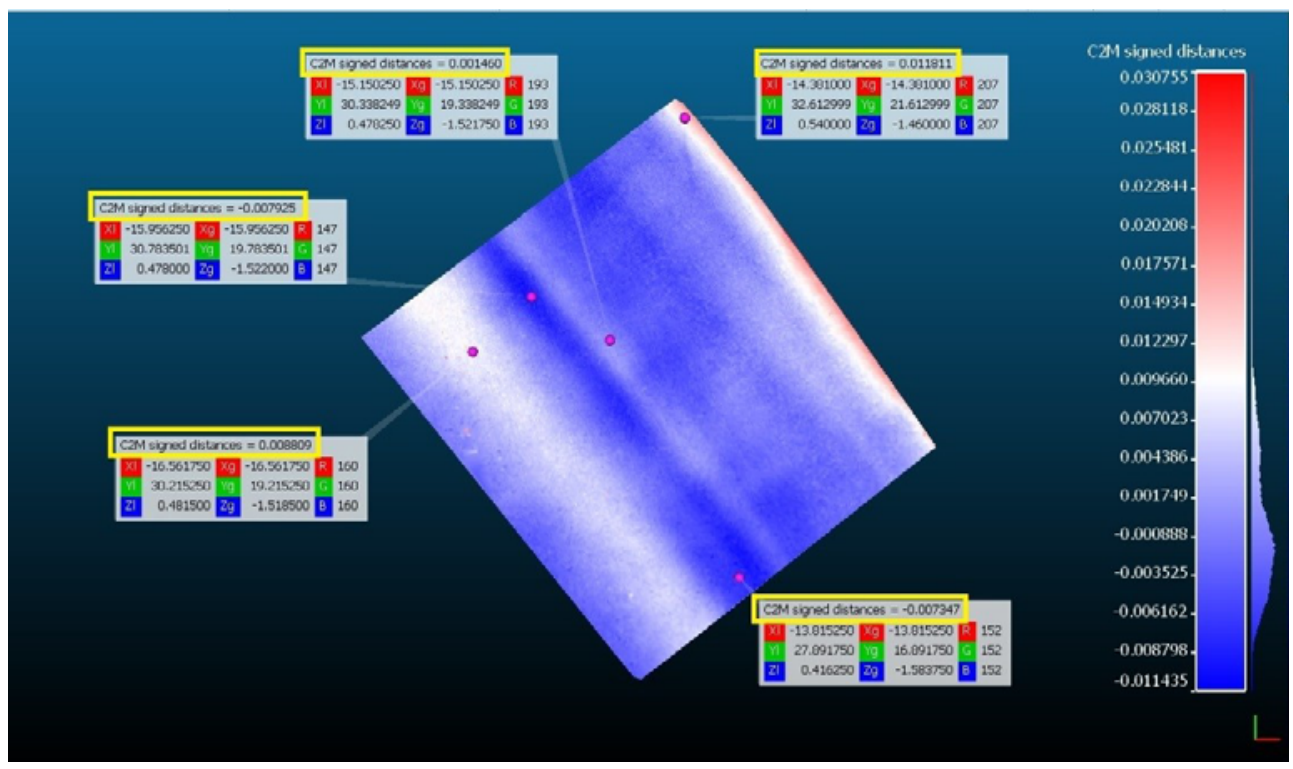

Fig. 6. Result of analysis of the segment (3.8 x 4.2 meters) asphalt creek (units - meters).

The drawings can be the basis for many conclusions about the state of the bus bays. The rating based on graphics is intuitive and makes it easy to identify ruts in an analysed area of road. The presented procedure can be widely used to analyse the geometry of flat objects when inventorying those objects.

\section{Conclusions}

In cities, the condition of roads is a very important factor because it determines driver and passenger comfort and safety [11]. The most degradable sections of the roads are bus bays. The authors analysed bus bays and the type of the pavement. To perform the experiment, the Riegl VZ-400 system was used, thanks to Apeks Company, Gdansk, Poland. Its innovative measuring method could be successfully used when searching for deformations. The experiment, described in this paper shows that of the two lay-bys taken into account, one is more deformed - a creek made of cobbles. In the case of this bay, the height differences are approximately $6 \mathrm{~cm}$. In contrast, in the case of the bay made of asphalt, this difference is much lower $-2 \mathrm{~cm}$. The proposed analytical process can be used in many other cases in transport construction (for example, to assess the condition of the surface geometry of roads, sidewalks or bicycle paths). Laser scanning technology has been used in transport construction for some time. An example may be a publication [12] describing the measurement of the clearance gauge of railways.

\section{References}

1. W. Kozłowski, Innovative Technological Solutions in Terms of Realizations Partial Renovation of Bituminous Roads Using SPRIDER, Procedia Eng. 161 pp. 503-510 (2016). doi:10.1016/j.proeng.2016.08.676

2. F. Li, S.S. Liao, M. Cai, A new probability statistical model for traffic noise prediction on free flow roads and control flow roads, Transp. Res. Part D Transp. Environ. 49 pp. 313-322 (2016). doi:10.1016/j.trd.2016.10.019 
3. Riegl VMZ-400 Infosheet, www.riegl.com, (n.d.)

4. K. Bobkowska, A. Inglot, M. Mikusova, P. Tysi?c, Implementation of Spatial Information for Monitoring and Analysis of the Area Around the Port Using Laser Scanning Techniques, Polish Marit. Res. 24 pp. 10-15 (2017). doi:10.1515/pomr2017-0015

5. J. Żukowska, Regional Observatory as a Part of Road Safety Information System, 11th Int. Conf. Transp. Syst. Telemat. (TST 2011). 239 pp. 409-416 (2011). doi:10.1007/978-3-642-24660-9_47

6. M. Budzyński, K. Jamroz, J. Pyrchla, W. Kustra, K. Pyrchla, Identifying the Effects of Selected Road and Roadside Parameters on Road Safety Using Geodetic Techniques, in: 2016 Balt. Geod. Congr. (BGC Geomatics), pp. 154-158 (IEEE, 2016). doi:10.1109/BGC.Geomatics.2016.35

7. P. Tysiac, A. Wojtowicz, J. Szulwic, Coastal Cliffs Monitoring and Prediction of Displacements Using Terrestial Laser Scanning, in: 2016 Balt. Geod. Congr. (BGC Geomatics), pp. 61-66 (IEEE, 2016). doi:10.1109/BGC.Geomatics.2016.20

8. B. Hejmanowska, W. Kaminski, M. Przyborski, K. Pyka, J. Pyrchla, Modern remote sensing and the challenges facing education systems in terms of its teaching, in: 7th Int. Conf. Educ. New Learn. Technol., pp. 6549-6558 (IATED, Barcelona, 2015)

9. A. Janowski, K. Nagrodzka-Godycka, J. Szulwic, P. Ziolkowski, Remote sensing and photogrammetry techniques in diagnostics of concrete structures, Comput. Concr. 18 pp. 405-420 (2016). doi:10.12989/cac.2016.18.3.405

10. D. Zai, Y. Guo, J. Li, H. Luo, Y. Lin, Y. Sun, P. Huang, C. Wang, 3D road surface extraction from mobile laser scanning point clouds, in: 2016 IEEE Int. Geosci. Remote Sens. Symp., pp. 1595-1598 (IEEE, 2016). doi:10.1109/IGARSS.2016.7729407

11. R. Bergel-Hayat, J. Żukowska, Road Safety Trends at National Level in Europe: A Review of Time-series Analysis Performed during the Period 2000-12, Transp. Rev. 35 pp. 650-671 (2015). doi:10.1080/01441647.2015.1030005

12. S. Mikrut, P. Kohut, K. Pyka, R. Tokarczyk, T. Barszcz, T. Uhl, Mobile Laser Scanning Systems for Measuring the Clearance Gauge of Railways: State of Play, Testing and Outlook, Sensors. 16 pp. 683 (2016). doi:10.3390/s16050683

13. A.I. Setianingsih, S. Sangaji, A. Setyawan, Road Maintenance and Rehabilitation Program Using Functional and Structural Assessment, IOP Conf. Ser. Mater. Sci. Eng. 176 pp. 12030 (2017). doi:10.1088/1757-899X/176/1/012030 